\title{
Biosynthesis, regulation, and engineering of microbially produced branched biofuels
}

\author{
Wenqin Bai $^{1 \dagger}$, Weitao Geng ${ }^{1 \dagger}$, Shaojie Wang ${ }^{1}$ and Fuzhong Zhang ${ }^{1,2,3^{*}}$ (1)
}

\begin{abstract}
The steadily increasing demand on transportation fuels calls for renewable fuel replacements. This has attracted a growing amount of research to develop advanced biofuels that have similar physical, chemical, and combustion properties with petroleum-derived fossil fuels. Early generations of biofuels, such as ethanol, butanol, and straightchain fatty acid-derived esters or hydrocarbons suffer from various undesirable properties and can only be blended in limited amounts. Recent research has shifted to the production of branched-chain biofuels that, compared to straight-chain fuels, have higher octane values, better cold flow, and lower cloud points, making them more suitable for existing engines, particularly for diesel and jet engines. This review focuses on several types of branched-chain biofuels and their immediate precursors, including branched short-chain (C4-C8) and long-chain (C15-C19)-alcohols, alkanes, and esters. We discuss their biosynthesis, regulation, and recent efforts in their overproduction by engineered microbes.
\end{abstract}

Keywords: Advanced biofuels, Branched fuels, Branched fatty acids, Branched alcohols, Cyclopropane fatty acid

\section{Introduction}

High petroleum prices and increasing concerns over energy security and climate change are driving the development of renewable biofuels in recent years $[1$, 2]. Bioethanol has been commercially used as a gasoline replacement in major markets of the world. However, this early generation of biofuel has several problems, such as low energy density and high hygroscopicity, leading to storage and transportation problems [3]. Recent development in microbial engineering has enabled the bioproduction of a suite of biofuel molecules, such as 1-butanol, isobutanol, limonene, hydrogenated farnesene, and fatty acid-derived alkanes, alkenes, alcohols, and esters [4-11]. Based on the chain length or the number of carbon atoms in their molecules, biofuels can be divided into shortchain (C4-C8), medium-chain (C9-C14), and long-chain (C15-C20) fuels. Based on their chain structures, biofuels can be divided into straight-chain or branched-chain

\footnotetext{
*Correspondence: fzhang@seas.wustl.edu

'Wenqin Bai and Weitao Geng contributed equally to this work 1 Department of Energy, Environmental and Chemical Engineering, Washington University in St. Louis, Saint Louis, MO 63130, USA Full list of author information is available at the end of the article
}

biofuels. Compared to straight-chain biofuels, their branched-chain counterparts often have better physical and combustion properties. Branched short-chain alcohols such as isobutanol and 3-methyl-1-butanol have higher octane values than their linear-chain counterparts $[3,12]$. Branched long-chain fuels offer improved properties such as lower freezing point, better cold flow, and lower cloud point, compared with their straight-chain counterparts $[13,14]$, which are vital to practical biofuel use at low temperature and high altitude, particularly for jet fuels.

While production of straight-chain biofuels has been extensively reviewed $[15,16]$, this review targets recent progress in the microbial synthesis and overproduction of branched biofuels and their immediate precursors. Current branched fuels mostly contain only methyl branches. Ethyl and higher branched structures are relatively rare in nature and have not been extensively engineered for energy applications. Branched short-chain alcohols and esters, such as isopentenol, isobutanol, 2-methyl-1-butanol, and 3-methyl-1-butanol, are mostly derived from branched $\alpha$-keto acids. Branched longchain fuels are mostly derived from lipid fatty acids. These two types of biofuels are the major focus of this 
review. Branched medium-chain biofuels can be derived by engineering the isoprenoid pathway, which has been excellently reviewed elsewhere $[16,17]$ thus will not be discussed here. Medium-chain biofuels can also be biosynthesized by truncating the intermediates during lipid fatty acid biosynthesis $[18,19]$, which will be discussed together with short- and long-chain fuels. Among the branched long-chain fuels, the position of the branch can be either at the terminus or the middle of the chain. These two types of compounds were synthesized by different routes of the lipid metabolic pathway and thus are discussed separately. For each pathway, we briefly discuss the natural function of the branched compounds that lead to the synthesis of biofuels, followed by an introduction of the pathway, its regulation, and recent engineering efforts in the overproduction of branched biofuels. General metabolic engineering strategies to improve titers, yields, and productivities have been reviewed elsewhere and will not be discussed [20-23]. Many of the advanced biofuels are in their early developmental stage; therefore, their scalable production and real-world application will not be the focus of this review.

\section{Branched short-chain biofuels}

In recent years, considerable advances have been achieved by engineering microorganisms to produce branched short-chain (C4-C8) alcohols and esters. These compounds were originally identified as flavor compounds in the food industry [24] and are derived from branched-chain $\alpha$-keto acids or amino acids via a pathway proposed by Ehrlich [25]. Because of the broad substrate range of the enzymes in the last two steps of the Ehrlich pathway, the pathway becomes the basis for production of a wide range of branched short-chain compounds, including branched biofuels [3]. Key genes in the Ehrlich pathway together with genes in the biosynthesis of $\alpha$-keto acids have been engineered to improve titers and yields of branched short-chain compounds in various microorganisms, such as Escherichia coli [3], Bacillus subtilis [26], Saccharomyces cerevisiae [27] and Ralstonia eutropha [28]. Similar to straight short-chain alcohols, branched short-chain alcohols interfere with cell membrane's function as a barrier, thus usually exhibiting cellular toxicity when produced in microbial hosts [29].

\section{Biosynthesis of branched short-chain alcohols and esters}

In the Ehrlich pathway (Fig. 1a), branched-chain amino acids (valine, leucine, and isoleucine) serve as the precursors and are first converted to the corresponding $\alpha$-keto acids (3-methyl-oxopentanoic acid, 4-methyl-oxopentanoic acid and 3-methyl-oxobutyric acid) by transaminase (TA). Branched-chain $\alpha$-keto acids can be also synthesized from carbohydrate feedstock, such as glucose, via pyruvate. Subsequently, these $\alpha$-keto acids are decarboxylated by $\alpha$-keto acid decarboxylase (KDC) to form the corresponding aldehydes (2-methylbutanal, isopentanal, and isobutanal). Finally, these aldehydes are oxidized by aldehyde dehydrogenase (ALDH) to branched short-chain fatty acids (2-methylbutyric acid, isovaleric acid, and isobutyric acid) or reduced by alcohol dehydrogenases (ADH) or aldehyde reductase (ALR) to branched short-chain alcohols (2-methylbutanol, isoamyl alcohol, and isobutanol). The alcohols can be combined with acylCoAs by alcohol acetyltransferases (ATFs) to form various esters.

\section{Regulation of the Ehrlich pathway in S. cerevisiae}

Both pathway-specific activators and general regulatory mechanisms participate in the regulation of higher alcohol production in the context of the Ehrlich pathway (Fig. 1b).

Iaqui et al. [30] first identified Aro80p as a pathwayspecific transcriptional activator involved in the induction of ARO9 transaminase and ARO10 $\alpha$-keto acid decarboxylase genes in the presence of the aromatic amino acid tryptophan, phenylalanine, and tyrosine. A WRCCGWSATTTRCCG motif in the aro10 and aro 9 promoters was needed for the binding of Aro80p [31]. Then, Lee et al. [32] found that aro 9 and aro10 transcription also requires the GATA activators (Gat1 and Gln3), which mediate the nitrogen catabolite repression by activating GATA genes in low nitrogen conditions. The result shows that Aro80p not only induces its target genes aro 10 and aro 9 by binding to their promoters, but also by the recruitment of the GATA activators. In addition, another activator Warlp was identified to induce the transcription of the transporter Pdr12 encoding gene $p d r 12$. The activator has a cis-acting element in the promoter of $p d r 12$ and becomes active upon phosphorylation in response to the nonphysiological substrates benzoate and sorbate [33].

In addition, the culture conditions would also regulate the Ehrlich pathway. Lee et al. [34] found that the heat shock stress was able to affect aro 10 and aro 9 transcription. The expression level of the aro10 and aro 9 genes in an aro80 knockdown strain suggests that their transcription is activated by Aro80 under heat shock stress in $S$. cerevisiae. Furthermore, the Ehrlich pathway is also regulated in a carbon and nitrogen source-dependent manner. For example, constitutive overexpression of the ARO10 decarboxylase gene does not increase the 3-phenylpyruvate decarboxylase activity during growth on a medium supplemented with glucose and ammonium sulfate. However, the replacement of either the ammonium sulfate with phenylalanine or glucose with ethanol results in 


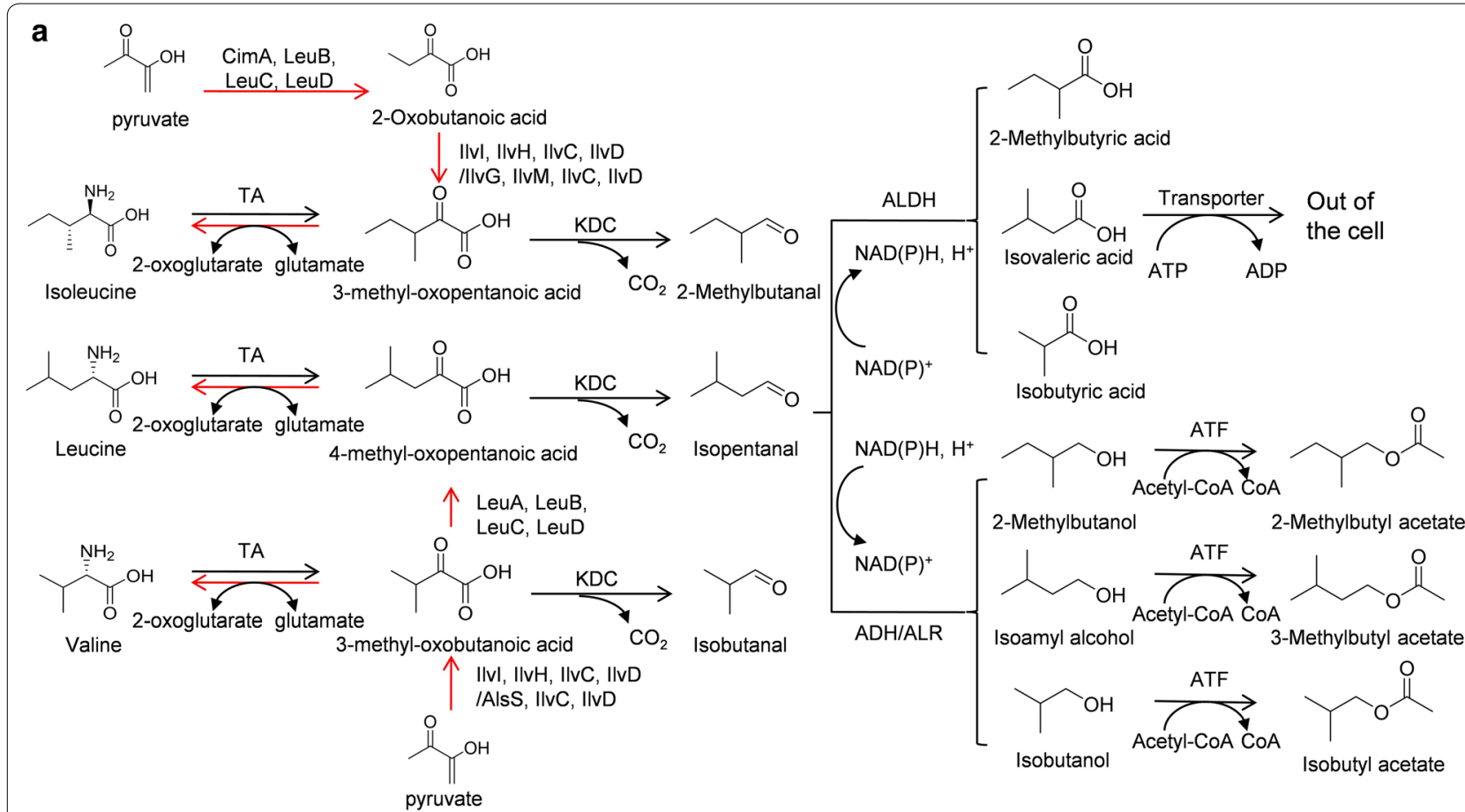

b

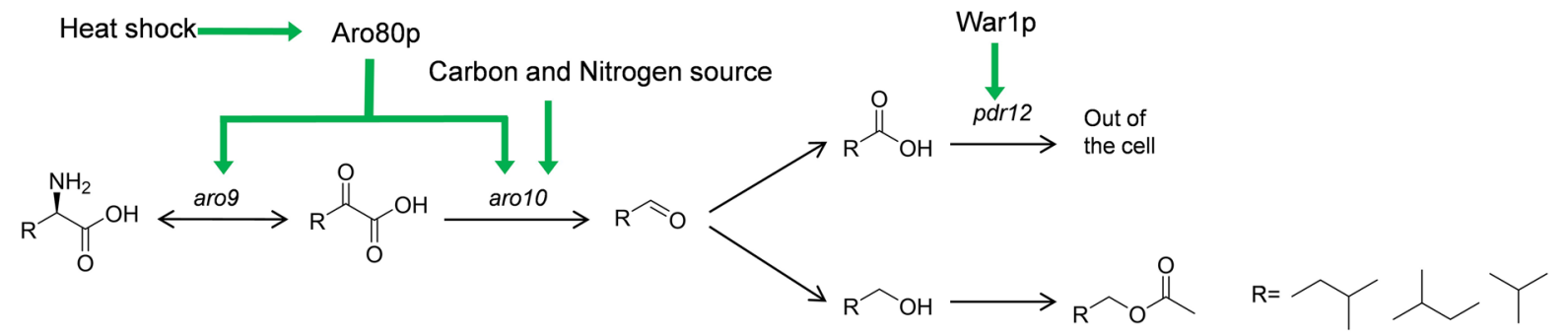

Fig. 1 Biosynthetic pathways of branched short-chain alcohols and esters and their regulation in S. cerevisiae. a Biosynthesis of branched-chain amino acids from pryurate is shown by red arrows. Ilvl: acetolactate synthase large subunit; IlvH: acetolactate synthase small subunit; IlvC: 2-hydroxy-3-ketol-acid reductoisomerase; IIvD: dihydroxy-acid hydratase; AlsS: acetolactate synthase; IlvG: acetolactate synthase II large subunit; IIvM: acetolactate synthase II large subunit; LeuA: 2-isopropylmalate synthase; LeuB: 3-propylmalate dehydrogenase; LeuC/D: isopropylmalate isomerase; CimA: citramalate synthase. The Ehrlich pathway in S. cerevisiae is shown in black arrows. TA: transaminase; KDC: a-ketoacid decarboxylase; ADH: alcohol dehydrogenases; ALDH: aldehyde dehydrogenase; ALR: aldehyde reductase; ATF: alcohol acetyltransferases. b A schematic overview of the regulation of branched short-chain alcohols and esters biosynthesis in S. cerevisiae

an obvious increase of 3-phenylpyruvate decarboxylase activity [35].

\section{Metabolic engineering for the production of branched short-chain alcohols and esters}

Current overproduction of branched short-chain biofuels is mainly focused on the optimization and/or modification of the Ehrlich pathways, the improvement of precursor pool, and the optimization of cofactor availability. $S$. cerevisiae has the natural ability to produce fatty alcohols. However, titers of branched short-chain biofuel in wild-type $S$. cerevisiae are very low $[25,36]$. To enhance the flux through the Ehrlich pathway, Kondo et al. [26] overexpressed $\alpha$-keto acid decarboxylase (KDC) from Lactococcus lactis and an alcohol dehydrogenase Adh6p from S. cerevisiae (Fig. 1a). Subsequently, the acetolactate synthase Ilv2, which catalyzes the first step of the valine synthetic pathway, was overexpressed to enhance the flux to 2-keto-3-methylvalerate. Meanwhile, the pyruvate decarboxylase PDC1 was eliminated to reduce the flux from pyruvate to ethanol. The resulting strain produced isobutanol at a titer of $143 \mathrm{mg} / \mathrm{L}$, which was 13-fold higher than that of the wild-type strain. Built upon this work, Matsuda et al. [37] further eliminated a competing 
pathway by deletion of the pyruvate dehydrogenase complex LPD1 and enhanced the cellular NADPH content by overexpression of the malate dehydrogenase MAE1, reaching an isobutanol titer of $1.62 \mathrm{~g} / \mathrm{L}$.

Besides producing branched short-chain alcohols and esters from their natural pathways in S. cerevisiae, the Ehrlich pathway has also been engineered in a series of heterologous hosts that lack the Ehrlich pathway but offer other fermentative advantages. These heterologous hosts include E. coli, B. subtilis, Corynebacterium glutamicum, Brevibacterium flavum R. eutropha, and Synechococcus elongatus 7942. One common strategy is reconstruction of the Ehrlich pathway in a heterologous host via combinatorial gene overexpression and optimization by deletion of key competing genes. For example, Atsumi et al. [3] constructed the Ehrlich pathway by expressing one of the five $\alpha$-keto acid decarboxylases (Pdc6p, Aro10p and Thi3p from S. cerevisiae, KIVD from L. lactics and PDC from Clostridium acetobutylicum) along with an alcohol dehydrogenases Adh2 from S. cerevisiae to produce isobutanol in E. coli. The engineered Ehrlich pathway uses endogenous $\alpha$-keto acids as precursors in E. coli, whose cellular pool was enhanced by deleting multiple competing pathways/enzymes, including an aldehyde-alcohol dehydrogenase (encoded by $a d h E$ ), a lactate dehydrogenase A (encoded by $l d h A$ ), a fumarate reductase (encoded by $f r d A B$ ), a regulator of fumarate and nitrate reduction (encoded by fur), and a phosphate acetyltransferase (encoded by pta) that contributes to by-product formation. In combination with the overexpression of the ilvIHCD genes for 2-ketoisovalerate biosynthesis, isobutanol was produced at a titer of $22 \mathrm{~g} / \mathrm{L}$. Similarly, $2.62 \mathrm{~g} / \mathrm{L}$ of isobutanol was produced in $B$. subtilis by engineering an Ehrlich pathway together with the overexpression of the acetolactate synthase genes (alsS, $i l v C$, and $i l v D$ as shown in Fig. 1) responsible for the synthesis of 2-ketoisovalerate [27]. C. glutamicum, the most widely used branched-chain amino acid producer in fermentation industry, has a natural ability to accumulate 2-ketoisovalerate and 2-keto-3-methylvalerate at high intracellular concentrations [38]. By overexpressing an $\alpha$-keto acid decarboxylase (encoded by aro 10 from $S$. cerevisiae) and an alcohol dehydrogenase (encoded by $y q h D$ from E. coli) and reducing the activity of the branchedchain amino acid transaminase, 3-methyl-1-butanol was produced at $2.76 \mathrm{~g} / \mathrm{L}$ [38]. The Ehrlich pathway has also been engineered in R. eutropha [28], leading to the production of 3-methyl-1-butanol and isobutanol at $140 \mathrm{mg} / \mathrm{L}$ using $\mathrm{CO}_{2}$ as the carbon source and electricity as reducing power, and in B. flavum [39], leading to the production of isobutanol, 2-methyl-1-butanol, and 3-methyl-1-butanol using duckweed as feedstock. In addition, branched short-chain alcohols can be produced in engineered cyanobacteria using $\mathrm{CO}_{2}$ as the carbon source and sunlight energy. In S. elongatus 7942, a 5-step heterologous biosynthetic pathway was engineered, leading to the production of isobutanol at $450 \mathrm{mg} / \mathrm{L}$ [40]. Table 1 summarizes the theoretical yields of the abovementioned biofuels, and their reported yields and titers in different hosts.

In addition, by overexpressing the endogenous alcohol acyltransferase (encoded by atf1) that catalyzes the condensation step of branched-chain alcohols with acetyl-CoA [41], isobutanol, 3-methyl-1-butanol, and 2-methyl-1-butanol were converted to isobutyl acetate, 3-methyl-1-butylacetate, and 2-methyl-1-butyl acetate with a titer of $260.2 \mathrm{mg} / \mathrm{L}, 296.1 \mathrm{mg} / \mathrm{L}$, and $289.6 \mathrm{mg} / \mathrm{L}$, respectively. For the biosynthesis of branched shortchain esters, Rodriguez et al. [42] engineered $E$. coli using the alcohol $O$-acyltransferase (ATF) from $S$. cerevisiae. By combining different acyl-CoA molecules found in nature with various alcohol biosynthetic pathways,

Table 1 Theoretical yields and achieved yields and titers of the branched biofuels in different hosts

\begin{tabular}{|c|c|c|c|c|c|c|c|c|c|c|c|c|c|c|c|}
\hline \multirow[t]{3}{*}{ Product } & \multirow{3}{*}{$\begin{array}{l}\text { Theoretical } \\
\text { yields } \\
\text { (g/g } \\
\text { glucose) }\end{array}$} & \multicolumn{14}{|c|}{ Achieved yields (g/g glucose) and titer ( $g / L)$ in different hosts } \\
\hline & & \multicolumn{2}{|l|}{ E. coli } & \multicolumn{2}{|c|}{ S. cerevisiae } & \multicolumn{2}{|c|}{ B. subtilis } & \multicolumn{2}{|c|}{$\begin{array}{l}\text { C. } \\
\text { glutamicum }\end{array}$} & \multicolumn{2}{|c|}{ B. flavum } & \multicolumn{2}{|c|}{ R. eutropha } & \multicolumn{2}{|c|}{ S. elongatus } \\
\hline & & Yield & Titer & Yield & Titer & Yield & Titer & Yield & Titer & Yield & Titer & Yield & Titer & Yield & Titer \\
\hline Isobutanol & 0.42 & $\begin{array}{l}0.42 \\
{[98]}\end{array}$ & $\begin{array}{l}50 \\
{[99]}\end{array}$ & $\begin{array}{l}0.016 \\
{[37]}\end{array}$ & $\begin{array}{l}1.6 \\
{[37]}\end{array}$ & $\begin{array}{l}0.066 \\
{[27]}\end{array}$ & $\begin{array}{l}2.6 \\
{[27]}\end{array}$ & $\begin{array}{l}0.32 \\
{[100]}\end{array}$ & $\begin{array}{l}72.69 \\
{[100]}\end{array}$ & $\begin{array}{l}0.089 \\
{[39]}\end{array}$ & $\begin{array}{l}5.36 \\
{[39]}\end{array}$ & - & $\begin{array}{l}0.85 \\
{[28]}\end{array}$ & - & $0.45[40]$ \\
\hline 3-methyl-1-butanol & 0.33 & $\begin{array}{l}0.11 \\
{[4]}\end{array}$ & $\begin{array}{l}9.5 \\
{[4]}\end{array}$ & $\begin{array}{l}0.0076 \\
{[101]}\end{array}$ & $\begin{array}{l}0.77 \\
{[101]}\end{array}$ & - & $\begin{array}{l}\text { Trace } \\
{[27]}\end{array}$ & $\begin{array}{l}0.10 \\
{[38]}\end{array}$ & $\begin{array}{l}2.8 \\
{[38]}\end{array}$ & $\begin{array}{l}0.013 \\
{[39]}\end{array}$ & $\begin{array}{l}0.79 \\
{[39]}\end{array}$ & - & $\begin{array}{l}0.57 \\
{[28]}\end{array}$ & - & - \\
\hline 2-methyl-1-butanol & 0.38 & $\begin{array}{l}0.17 \\
{[102]}\end{array}$ & $\begin{array}{l}1.25 \\
{[102]}\end{array}$ & $\begin{array}{l}0.0045 \\
{[103]}\end{array}$ & $\begin{array}{l}0.18 \\
{[103]}\end{array}$ & - & $\begin{array}{l}\text { Trace } \\
{[27]}\end{array}$ & $\begin{array}{l}0.02 \\
{[38]}\end{array}$ & $\begin{array}{l}0.37 \\
{[38]}\end{array}$ & $\begin{array}{l}0.032 \\
{[39]}\end{array}$ & $\begin{array}{l}1.95 \\
{[39]}\end{array}$ & - & - & - & - \\
\hline $\mathrm{C}_{17: 0(1)}^{\mathrm{a}}$ & 0.34 & $0.010[59]$ & $\begin{array}{l}0.21 \\
{[59]}\end{array}$ & - & - & - & - & - & - & - & - & - & - & - & - \\
\hline
\end{tabular}

${ }^{a}$ Terminally branched LCFAs were always produced as mixtures, here the theoretical yield was calculated assuming a single product of $C_{17: 0(1)}$ 
a multitude of esters were obtained. In particular, they achieved high-level production of isobutyl acetate from glucose $(17.2 \mathrm{~g} / \mathrm{L})$. Wax ester synthase/acyl-coenzyme A: diacylglycerol acyltransferase (WS/DGAT), which catalyzes the esterification of fatty acyl-CoAs and short-chain alcohols, was also introduced into E. coli for the biosynthesis of fatty acid short-chain esters (FASE). A titer of $209 \pm 2.6 \mathrm{mg} / \mathrm{L}$ FASEs, $50 \%$ of which being fatty acid branched-chain esters (FABCEs), was obtained [43].

\section{Terminally branched long-chain fuels}

Long-chain fatty acids (LCFAs) in the range of C14$\mathrm{C} 20$ are the major membrane component for almost all organisms except for a few archaea species, which have isoprenoid-derived membranes [44]. While the most common LCFAs have straight chains, some Gram-positive organisms, such as the Bacilli, Staphylococci, and Streptomycetes, produce terminally methyl-branched LCFAs as the acyl constituents of membrane lipids. The methyl branch is usually found at either the $\omega-2$ or $\omega-3$ position of the acyl group and is called iso- or anteisobranched fatty acids, respectively [45]. These terminally branched LCFAs are believed to increase the fluidity and lower the phase transition temperature of their lipid components [46]. Similarly, branched LCFA-derived biofuels have significantly lower melting temperatures than their straight-chain counterparts, offering improved cold flow properties [13].
Biosynthesis of terminally branched long-chain fatty acids The biosynthetic pathway of terminally branched LCFAs in B. subtilis is well characterized [47-49] as shown in Fig. 2. This pathway used branched-chain $\alpha$-keto acids as the precursors [49], which are first activated to short-chain acyl-CoAs by branched-chain $\alpha$-keto acid dehydrogenases (BKD, encoded by the $b k d$ operon). C4 and C5 branched-chain acyl-CoAs are the primer for the biosynthesis of terminally branched LCFAs, and malonyl-CoA is the chain extender of the primer. $\beta$-ketoacyl-acyl carrier protein synthase III $(\mathrm{FabH})$ catalyzes the first condensation step by condensing branched-chain acyl-CoAs with malonylacyl carrier protein (malonyl-ACP). The resulting $\beta$-ketoacyl-ACP is then elongated through repeated cycles of reactions catalyzed by the multienzyme fatty acid type II biosynthesis system (FASII) to yield terminally branched long-chain acyl-ACPs. Thioesterase can hydrolyze long-chain acyl-ACPs to produce free terminally branched LCFAs. Depending on the $\alpha$-keto acid precursor, different terminally branched LCFA species can be formed [48]. For example, 3-methyl-oxobutyric acid can be converted to isobutyryl-CoA, which yields even-numbered iso-C14:0 and iso-C16:0 fatty acids. Precursors 4-methyl-oxopentanoic acid and 3-methyloxopentanoic acid will yield odd-numbered isobranched and anteiso-branched C15:0 and C17:0 fatty acids, respectively [50].

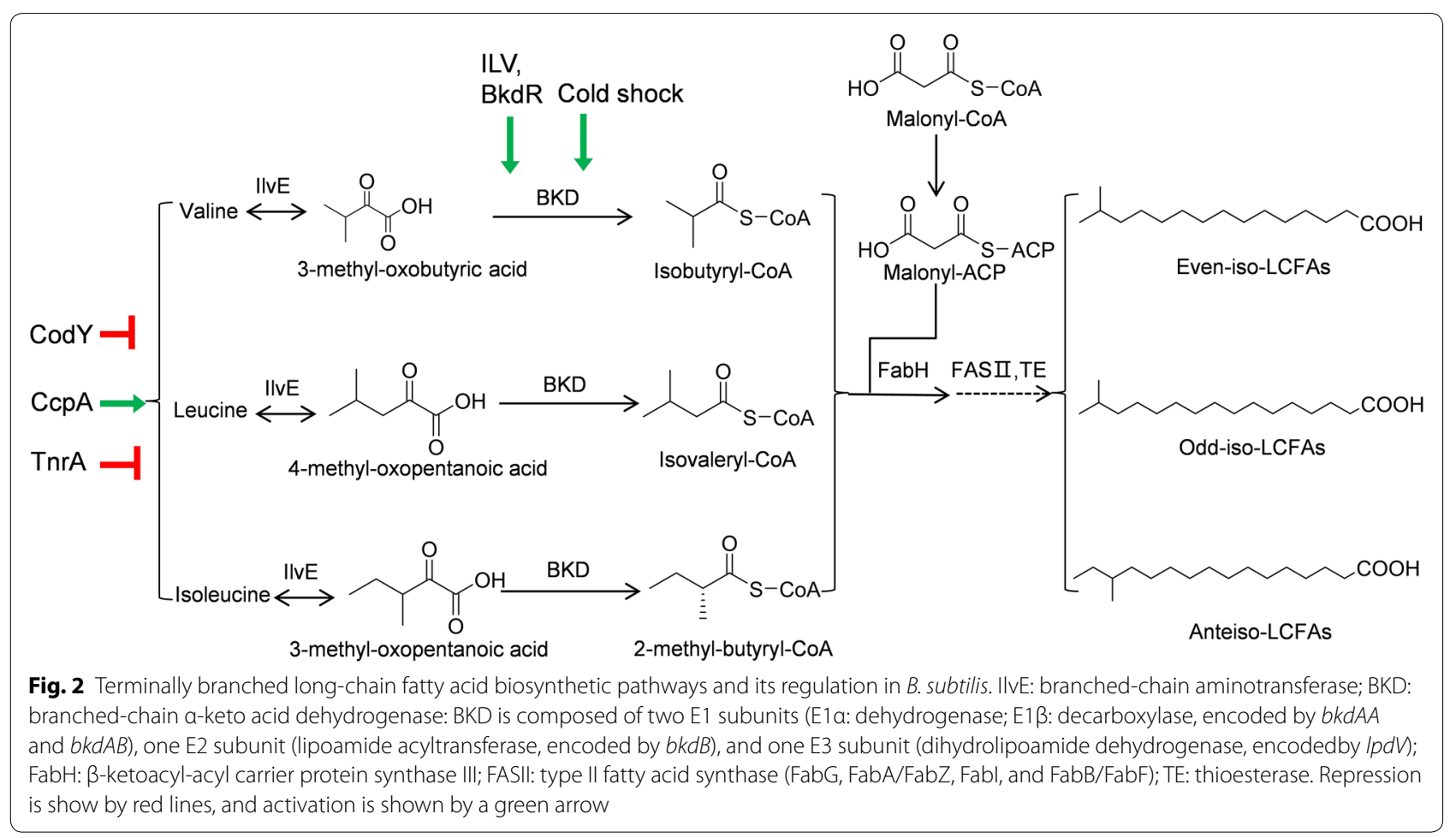




\section{Regulation of terminally branched LCFA biosynthesis in Gram-positive bacteria}

The plasma membrane of some Gram-positive bacteria contains a mixture of straight- and branched-chain lipids. Cells vary the proportion of branched-chain fatty acids to modulate membrane fluidity. Thus, regulating the biosynthesis of terminally branched LCFAs become important to cell fitness. In these bacteria, at least three layers of regulation of their LCFA composition are identified: (1) control the $\alpha$-keto acid precursor pools, (2) selective expression of the $b k d$ operon, and (3) control FabH substrate preferences (Fig. 2).

The ilvB operon involved in the biosynthesis of $\alpha$-keto acids is regulated by CodY, a global transcriptional repressor [51]. Activation of CodY by guanosine triphosphate (GTP) and branched-chain amino acids allows CodY to bind to the promoter region of $i l v B$, leading to inhibition of $\alpha$-keto acid biosynthesis [52]. In addition, the $i l v B$ operon can also be transcriptionally activated by CcpA in response to glucose and repressed by TnrA in response to nitrogen [53].

The $B$. subtilis bkd operon is also regulated by several factors [54]. The promoter of the $b k d$ operon is regulated by the sigma factor SigL, a member of the sigma 54 family. Transcription initiation from the $b k d$ operon requires an activator protein $\mathrm{BkdR}$, which interacts with an upstream activating sequence. The DNA binding activity of BkdR can be further enhanced by branched-chain amino acids as demonstrated in Pseudomonas putida, [55]. Additionally, cold shock can effectively stabilize $b k d$
mRNAs, increasing the content of branched-chain fatty acids [56].

When exposed to cold temperatures, some Grampositive bacteria predominantly increase the proportion of low-freezing anteiso-branched LCFAs relative to isoand straight LCFAs in its membrane [50]. For example, the Listeria monocytogenes FabH showed a higher preference for 2-methylbutyryl-CoA, the precursor of oddnumbered anteiso-LCFAs, at $10{ }^{\circ} \mathrm{C}$ than that at $30{ }^{\circ} \mathrm{C}$. The temperature-dependent substrate selectivity of FabH underlies the increased formation of anteiso-LCFAs during low-temperature adaptation [57].

\section{Metabolic engineering for the production of terminally branched long-chain fatty acids and their derivatives}

Recent advances in metabolic engineering have enabled the overproduction of terminally branched LCFAs in microbial hosts that naturally do not produce branched lipids. These engineering efforts have largely expanded the capability to bioproduce advanced biofuels in microbial hosts that have more attractive features than the native host [49]. By overexpressing the B. subtilis $f a b H 2$ and its $b k d$ operon, a terminally branched LCFA biosynthetic pathway was first constructed in E. coli (Fig. 3) [8]. However, the initially engineered strain only produced $2.5 \mathrm{mg} / \mathrm{L}$ of branched-chain LCFAs. Instead, a high proportion of straight-chain fatty acids were coproduced [8]. To increase the proportion of terminally branched LCFAs in total free fatty acids, Jiang et al. [58] replaced the acetyl-CoA-specific E. coli FabH with

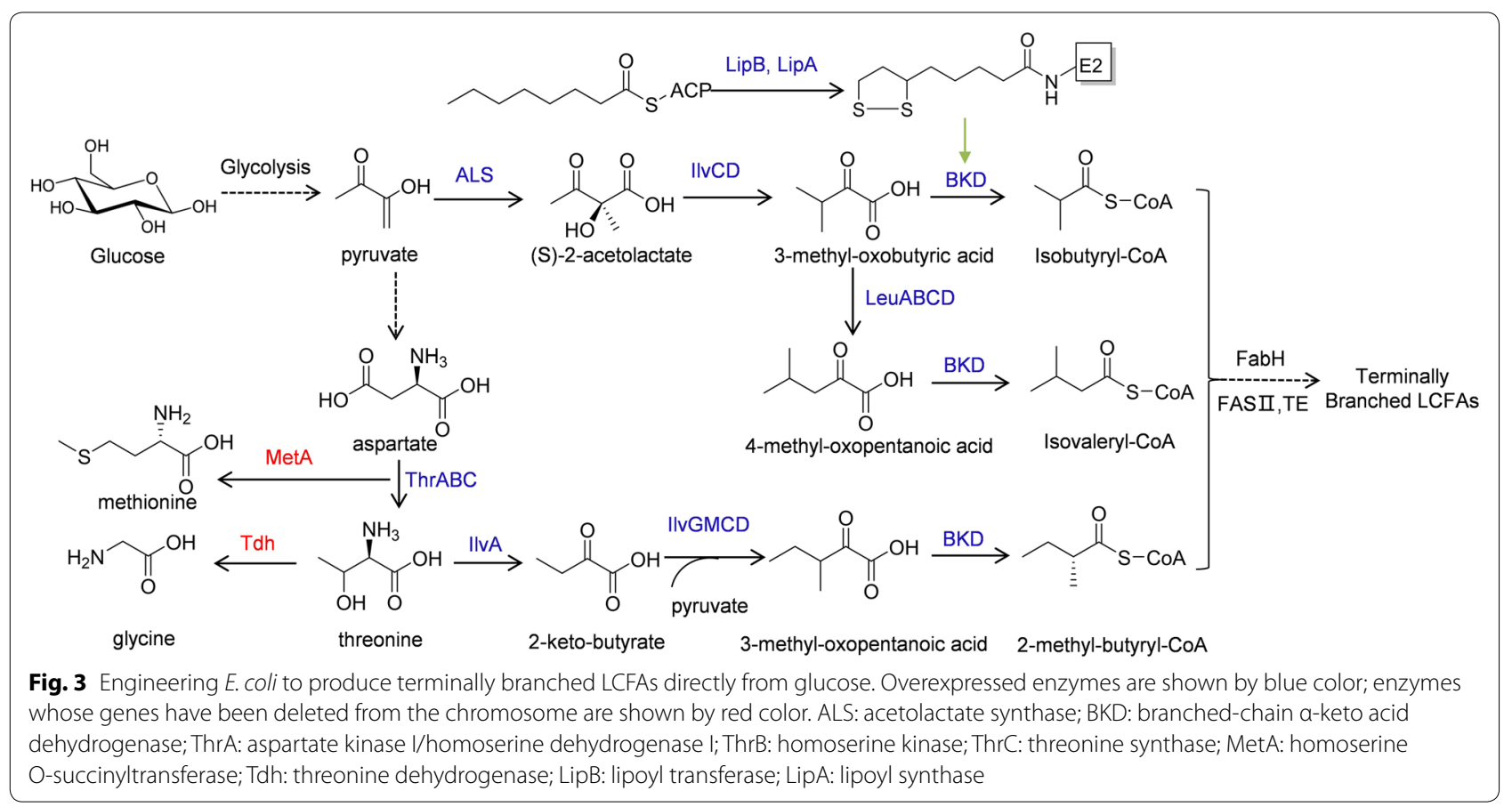


a branched-chain-acyl-CoA-specific FabH and found that this replacement directed the flux to the synthesis of terminally branched LCFAs and increased the terminally branched LCFAs titer by 48 -fold. Later, it was found that overexpression of the $b k d$ operon depleted the cellular lipoylation capability of the host, preventing the proper lipoylation of two E. coli native $\alpha$-keto acid dehydrogenases, including the essential 2-oxoacid dehydrogenase $(\mathrm{OADH})$ and the pyruvate dehydrogenase (PDH), thus inhibiting cell growth and terminally branched LCFAs production [59]. To solve this problem, an endogenous protein lipoylation pathway was engineered (Fig. 3). This pathway contains a lipoyl (octanoyl) transferase (LipB, encoded by lipB) that transfers an octanoyl moiety from octanoyl-ACP to the E2 subunit of $\alpha$-keto acid dehydrogenases and a lipoyl synthase (LipA, encoded by lipA) that inserts two sulfur atoms into the octanoyl side chain of the octanoylated E2 subunit, forming a lipoyl group. The engineered protein lipoylation pathway not only restored the function of all $\alpha$-keto acid dehydrogenases, but also increased the terminally branched LCFA titer to $207 \mathrm{mg} / \mathrm{L}$ [59]. Incorporation of the terminally branched LCFAs into the lipid membrane is expected to affect membrane fluidity and permeability, resulting in cellular stress. However, analysis of previously engineered LCFA-producing strains showed little incorporation of branched LCFAs into cell membrane [59].

While most Gram-positive bacteria produce both iso- and anteiso-LCFAs as a mixture, for practical applications, it is desirable to engineer strains that can specifically produce one type of terminally branched LCFAs. This has been achieved mostly by controlling the supply of $\alpha$-keto acid precursors. When overexpressing the B. subtilis alsS and the E. coli ilvCD (Fig. 3), flux through 3-methyl-2-oxobutyric acid was enhanced, leading to even-chain-iso-fatty acid as the major terminally branched LCFA species (65\%) [58]. When the leuABCD operon containing a feedback-resistant mutant of leuA was overexpressed, biosynthesis of 4-methyl-2-oxopentanoic acid was enhanced (Fig. 3), making the odd-chainiso-fatty acids the predominant terminally branched LCFA products (89\%) [58].

In addition, anteiso-branched LCFAs were produced as the major branched LCFA species by overexpressing the Salmonella typhimurium ilvGMCD, the C. glutamicum $i l v A$, and the E. coli thr $A B C$ to enhance the flux through 3-methyl-oxopentanoic acids and by dynamically regulating $\mathrm{fabH}$ expression (Fig. 3). The resulting strain produced anteiso-branched fatty acids up to $20.4 \%$ of total free fatty acids [60]. Overall, by engineering $\alpha$-ketoacid biosynthetic pathways, compositions of terminally branched LCFAs can also be controlled.
Besides the overproduction of terminally branched LCFAs, some metabolic engineering works on the production of branched alkanes, alcohols, and esters have also been reported $[7,8]$. Branched alkanes, as ideal biofuels, are structurally and chemically similar to fossil fuels. Howard et al. [8] introduced the fatty acid reductase complex from Photorhabdus luminescens and an aldehyde decarbonylase from Nostoc punctiforme into $E$. coli with a terminally branched LCFA biosynthetic pathway, yielding methyl pentadecane. The results clearly demonstrate the feasibility of engineering artificial pathways for branched alkane biosynthesis in a microbial host. Branched long-chain fatty alcohols (BLFLs) in the range of $\mathrm{C} 12$ to $\mathrm{C} 18$ are more suitable as diesel fuel replacements than their straight-chain counterparts. Jiang et al. [7] constructed and tested the efficiencies of four different biosynthetic pathways that convert branched acyl-ACPs to BLFLs in E. coli. A modular engineering approach was then used to balance the flux between $\alpha$-keto acid synthesis, acyl-ACP generation, and alcohol formation. The best performing strain produced BLFLs at $350 \mathrm{mg} / \mathrm{L}$, where $75 \%$ of the produced fatty alcohols were BLFLs. In addition, Tao et al. [61] combined the branched short-chain alcohol and the branched LCFA biosynthetic pathways in E. coli, and produced LCFA esters containing methyl branches at both acid and alcohol moieties at $35 \mathrm{mg} / \mathrm{L}$ with a yield of $1.9 \mathrm{mg} / \mathrm{g}$ glycerol.

\section{Internally branched fatty acid-derived fuels}

Compared to straight and terminally branched LCFAs, internally branched LCFAs are relatively rare in nature. Thermophilic bacterium Rubrobacter xylanophilus produces 12-methylhexadecanoic acid and 14-methyloctadecanoic acid as the major fatty acid species in its lipids [62]. 13-Methylhexadecanoic acid was identified in Leptogorgia piccolo [63], and 9- and 12-methyltetradecanoic acids were found in cyanobacterium Scytonema sp. [64]. The best characterized internally branched LCFA is tuberculostearic acid (TSBA, 10-methylstearic acid) that is produced by Mycobacterium tuberculosis and related species [65]. TSBA is used as a clinical marker for the diagnosis of tuberculous and may play an important role in the persistent phase of infection [66]. Similarly, cyclopropane fatty acids (CFAs) that contain a cyclopropane ring represent another class of internally methylbranched LCFAs. CFAs are major lipid components of many bacteria, such as E. coli, S. typhimurium, and $M$. tuberculosis. They are also found in the seed oils of some higher plants including Malvales, Fabales, and Sapindales [67]. The position of the methyl group has strong effects to physical properties of branched LCFAs and their derived biofuels, with the greatest effect occurring 
at the mid of the acyl chain [68]. For example, internally branched LCFAs have even lower freezing points compared with terminally branched LCFAs [69]. Therefore, internally branched LCFA-derived biofuels are more promising than those derived from terminally branched LCFAs. Until now, there has not been much engineering work toward the overproduction of internally branched LCFAs. Thus, we will focus on the recent developments on the understanding of their biosynthesis.

\section{Biosynthesis of internally branched LCFAs}

In $M$. tuberculosis and related species, TSBA has been found in multiple phospholipids such as phosphatidylethanolamine (PE), phosphatidylinositol (PI), and diphosphatidylglycerol (DPG), and glycolipids such as phosphatidylinositol mannosides and lipoarabinomannans [70]. These glycolipids are virulence determinants associated with $M$. tuberculosis and are likely involved in subverting the immune system [71]. Only small amounts of TBSA can be detected in purified triglycerides (TAGs) [72], indicating that the TSBA pathway enzymes recognize specific phospholipid substrates (Fig. 4a).

The mechanism for TSBA synthesis is still not fully understood. It was hypothesized that the biosynthesis of TSBA involves two reaction steps (Fig. 4b). The first step is the methylenation of the oleic acid (18:1 $\Delta 9)$ moiety of phospholipids by a methyltransferase using S-adenosylL-methionine (SAM) as the methyl donor. The second step is the reduction of the intermediates, which are believed to be 10-methylene-octadecanoyl phospholipids, by a reductase using NADPH as the cofactor [73]. Meena et al. [74] demonstrated that a methyltransferase encoded by umaA from $M$. tuberculosis $\mathrm{H} 37 \mathrm{Rv}$ is capable of converting the oleoyl-phosphatidylcholine (PC) to TSBA-PC in vitro. Meena et al. [75] also showed that another methyltransferase encoded by $u f a A 1$ can also catalyze the formation of TSBA. Purified recombinant UfaA1 protein can convert oleoyl-phosphatidylcholine and oleoyl-PE to TSBA-PC and TSBA-PE in the presence of SAM and NADPH. However, neither umaA nor $u f a A 1$ has any functional domain associated with redox reactions. Machida et al. [45] later identified a gene cluster from Mycobacterium chlorophenolicum that is responsible for TSBA production. In this cluster, the $b f a B$ gene encodes a SAM-dependent methyltransferase, and the $b f a A$ gene encodes a FAD-dependent oxidoreductase. Heterologous expression of these two genes in E. coli produced TSBA from oleic acid, confirming their functions. These two enzymes, $\mathrm{BfaA}$ and $\mathrm{BfaB}$, were found to have surprisingly high regioselectivity, only converting 18:1 $\Delta 9$,

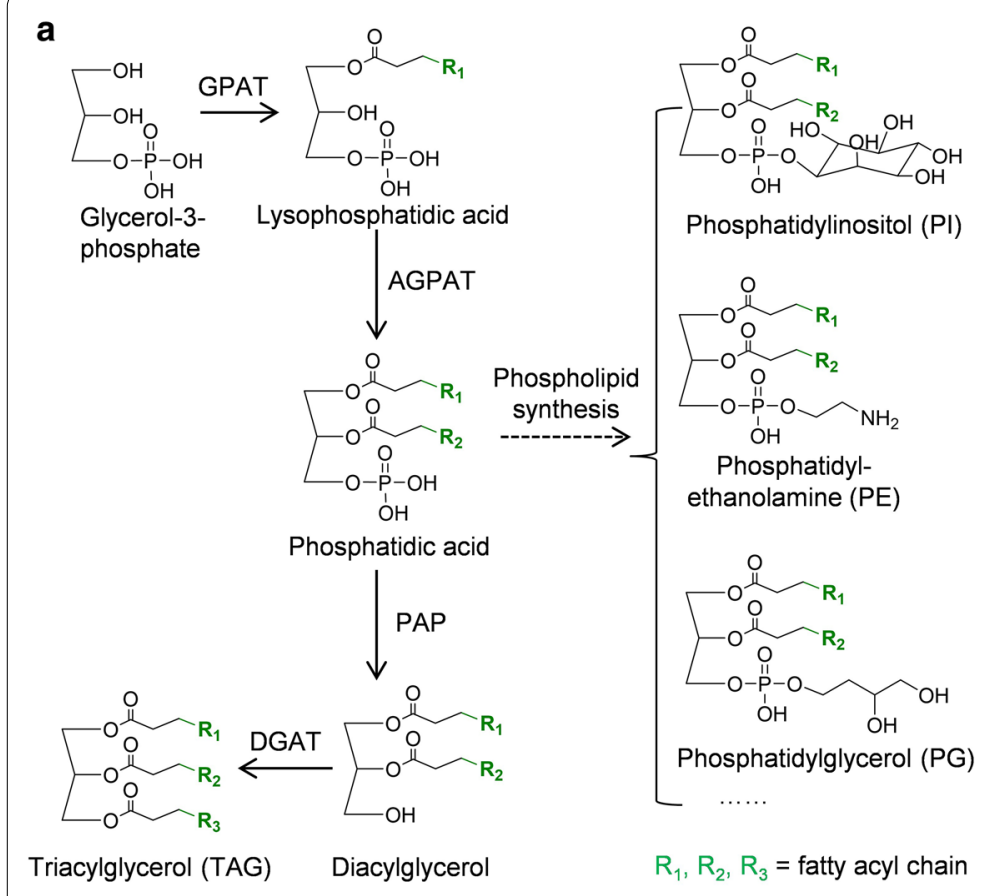

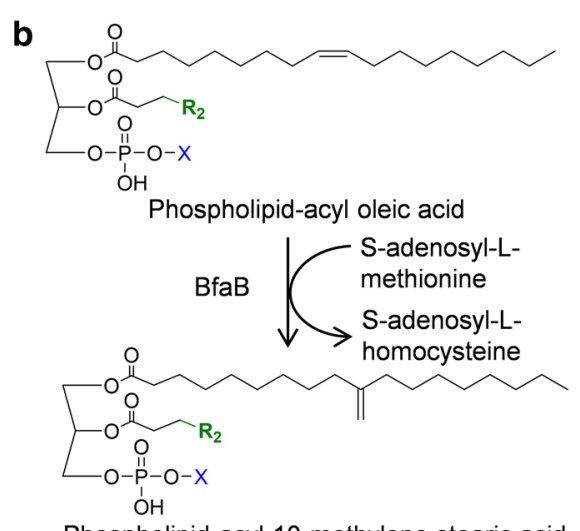

Phospholipid-acyl 10-methylene stearic acid

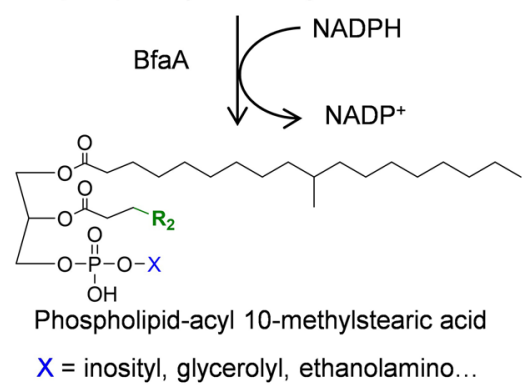

Fig. 4 Phospholipid and tuberculostearic acid biosynthetic pathway. a The Kennedy pathway for triacylglycerol and phospholipid biosynthesis. GPAT: glycerol-3-phosphate acyl transferase; AGPAT: acylglycerol-3-phosphate acyl transferase; PAP: phosphatidic acid phosphatase; DGAT: diacylglycerol acyl transferase. b Proposed pathway for tuberculostearic acid biosynthesis. BfaB: S-adenosyl-L-methionine-dependent methyltransferase; BfaA: FAD-binding oxidoreductase 
but not $16: 1 \Delta 9$ nor $18: 1 \Delta 11$ to branched fatty acids when tested in E. coli. Furthermore, it is not clear which phospholipids can be the substrates of the TSBA enzymes. Additionally, because unsaturated fatty acids (UFAs) are usually located at the $s n-2$ position of phospholipids in $E$. coli, TSBAs produced in $E$. coli are likely located at $s n-2$ position [76]. Meanwhile, in mycobacteria, TSBA is usually found at the $s n-1$ position of phospholipids. These results suggest that $\mathrm{BfaA}$ and $\mathrm{BfaB}$ might be able to convert UFAs at both $s n-1$ and $s n-2$ positions of phospholipids [77, 78]. Further studies are needed to illuminate their substrate specificities.

\section{Biosynthesis of CFAs}

Similar to other branched LCFAs, CFAs are also believed to modulate the fluidity and stability of cell membranes. CFAs are important to improve cell survival when microbes are subjected to environmental stresses such as high osmotic pressure [79], high (low) temperature [79, 80], low $\mathrm{pH}$ [81], and organic solvent conditions [82]. Specifically, an increased level of CFAs was observed in E. coli after exposure to $\mathrm{pH} 4$ for $16 \mathrm{~h}$ [83]. Deletion of CFA biosynthetic genes in $P$. putida results in decreased cell tolerance to organic solvents [84]. Additionally, CFAs also play an important role in bacterial virulence and persistence. For example, deletion of the M. tuberculosis pcaA gene, which encodes a CFA synthase and acts on $\alpha$-mycolates, inhibits $M$. tuberculosis from killing infected mice [85].

Biosynthesis of CFAs is catalyzed by cyclopropane fatty acid synthase (Cfa), which transfers a methylene group from SAM to the double bond of UFAs, creating a cyclopropane ring on the alkyl chain (Fig. 5). CFAs are typically produced from preexisting cis-UFAs of phospholipids through the Kennedy pathway (Fig. 4a). Therefore, most natural CFAs retain the cis configuration [86]. An in vitro study of the $E$. coli Cfa indicates that this enzyme has activities on different types of phospholipids including PE, phosphatidylglycerol (PG), cardiolipin (CL), and PC. In addition, the E. coli Cfa was reported to prefer preferentially act the $s n-2$ position of phospholipids [87], whereas Cfa from Sterculia foetida acts on sn-1 position [88].

The formation of CFAs occurs at the onset of the stationary phase in the cell growth cycle and continues until all of the cis-UFAs of the membrane phospholipid bilayers are converted into CFAs. This growth phasedepended regulation of CFA synthesis is caused by a RpoS-dependent promoter, which is activated only when cells enter stationary phase. In addition, the activity of the Cfa protein is also believed to be controlled by an unidentified energy-independent protease that is transcribed by a RpoH-dependent promoter [89].

Although CFAs has not been currently used as biofuels, their lower melting temperature compared to straight LCFAs and improved stability against oxidation compared to unsaturated FAs have made them promising biofuel targets as recently explored [90]. By introducing the cfa gene from E. coli into cyanobacterium Synechocystis sp. PCC 6803, CFAs were produced in engineered cells with up to $30 \%$ of total fatty acids [90]. In addition, engineering their biosynthesis could improve the tolerance of bacterial host to harsh conditions. For example, overexpression of $c f a$ in C. acetobutylicum ATCC 824 showed an increased butanol tolerance [91], while a $c f a$-deficient E. coli [92] or S. typhimurium [93] was very sensitive to acid stress. Yu et al. [94] expressed the E. coli cfa gene in the seeds of Arabidopsis and resulted the accumulation of CFAs up to $9.1 \%$. By coexpressing a Sterculia foetida lysophosphatidic acid acyltransferase (SfLPAT), the CFA content was further increased to $35 \%$.

\section{Conclusions}

We reviewed the progress of branched-chain biofuels, including branched short- and long-chain alcohols, alkanes, and esters. As we understand more about the biochemistry and regulation of lipid biosynthesis, novel metabolic pathways have been continuously developed, leading to new generations of biofuels with structures and properties highly similar to or identical

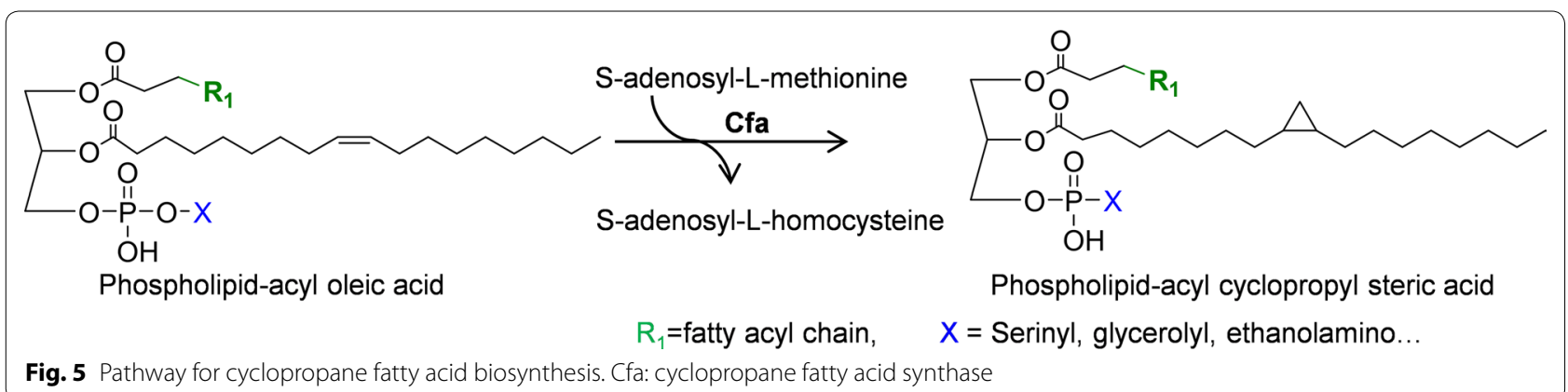

Fig. 5 Pathway for cyclopropane fatty acid biosynthesis. Cfa: cyclopropane fatty acid synthase 
with existing petroleum-derived fuels. The reviewed studies have proved the concept of producing advanced biofuels from engineered microorganisms; however, current titers and yields are still too low for economically viable production. These challenges demand efficient metabolic engineering tools to improve pathway yields, titers, and production stability of engineered microbial strains. Fortunately, some tools are already emerging and used for biofuel production, for example, modeling-guided pathway optimization [95], metabolite biosensor-enabled high-throughput screening and dynamic pathway regulation [96], and microbial population control tools to improve ensemble production [97]. Additionally, there is a clear trend to move these pathways and engineering strategies into industryrelevant microbial hosts. Hopefully, these current and future efforts will enable the conversion of various low-cost, abundant and environmental-friendly feedstock into advanced branched-chain fuels at high titers, yields, and productivities in industry-relevant scales.

\begin{abstract}
Abbreviations
ACP: acyl carrier protein; ADH: alcohol dehydrogenases; AGPAT: acylglycerol3-phosphate acyl transferase; ALDH: aldehyde dehydrogenase; ALR: aldehyde reductase; ALS: acetolactate synthase; ATF: alcohol acetyltransferases; BKD: branched-chain a-keto acid dehydrogenases; BLFL: branched long-chain fatty alcohol; CFA: cyclopropane fatty acids; CL: cardiolipin; DGAT: diacylglycerol acyl transferase; DPG: diphosphatidylglycerol; FabH: $\beta$-ketoacyl-acyl carrier protein synthase III; FASII: type II fatty acid biosynthesis system; GPAT: glycerol-3-phosphate acyl transferase; KDC: a-ketoacid decarboxylase; LCFAs: long-chain fatty acids; OADH: 2-oxoacid dehydrogenase; PDC: pyruvate decarboxylase; PDH: pyruvate dehydrogenase; PC: phosphatidylcholine; PE: phosphatidyl ethanolamine; PG: phosphatidylglycerol; PI: phosphatidylinositol; PAP: phosphatidic acid phosphatase; SAM: S-adenosyl-_-methionine; TE: thioesterase; UFA: unsaturated fatty acid.
\end{abstract}

\section{Authors' contributions}

WB wrote the introduction, terminally branched long-chain fuels and conclusion sections. SW wrote internally branched fatty acid-derived fuels section. WG wrote branched short-chain biofuels section. FZ designed, conceived, and critically revised it. All authors read and approved the final manuscript.

\section{Author details}

1 Department of Energy, Environmental and Chemical Engineering, Washington University in St. Louis, Saint Louis, MO 63130, USA. ${ }^{2}$ Division of Biological \& Biomedical Sciences, Washington University in St. Louis, Saint Louis, MO 63130, USA. ${ }^{3}$ Institute of Materials Science \& Engineering, Washington University in St. Louis, Saint Louis, MO 63130, USA.

\section{Competing interests}

The authors declare that they have no competing interests.

\section{Availability of data and materials}

Not applicable.

\section{Consent for publication}

The authors have consented for publication.

Ethics approval and consent to participate Not applicable.

\section{Funding}

This work was supported by the Department of Energy (DESC0018324) and the National Science Foundation (MCB1453147).

\section{Publisher's Note}

Springer Nature remains neutral with regard to jurisdictional claims in published maps and institutional affiliations.

Received: 1 November 2018 Accepted: 3 April 2019

Published online: 13 April 2019

\section{References}

1. Hill J, Nelson E, Tilman D, Polasky S, Tiffany D. Environmental, economic, and energetic costs and benefits of biodiesel and ethanol biofuels. Proc Natl Acad Sci U S A. 2006;103:11206-10.

2. Kerr RA, Service RF. What can replace cheap oil—and when. Science. 2005;309:101-101.

3. Atsumi S, Hanai T, Liao JC. Non-fermentative pathways for synthesis of branched-chain higher alcohols as biofuels. Nature. 2008;451:86-9.

4. Connor MR, Cann AF, Liao JC. 3-Methyl-1-butanol production in Escherichia coli: random mutagenesis and two-phase fermentation. Appl Microbiol Biotechnol. 2010;86:1155-64.

5. Wang B, Wang J, Zhang W, Meldrum DR. Application of synthetic biology in cyanobacteria and algae. Front Microbiol. 2012;3:344.

6. Zhang F, Rodriguez S, Keasling JD. Metabolic engineering of microbial pathways for advanced biofuels production. Curr Opin Biotechnol. 2011;22:775-83.

7. Jiang W, Qiao JB, Bentley GJ, Liu D, Zhang F. Modular pathway engineering for the microbial production of branched-chain fatty alcohols. Biotechnol Biofuels. 2017;10:244.

8. Howard TP, Middelhaufe S, Moore K, Edner C, Kolak DM, Taylor GN, Parker DA, Lee R, Smirnoff N, Aves SJ, Love J. Synthesis of customized petroleum-replica fuel molecules by targeted modification of free fatty acid pools in Escherichia coli. Proc Natl Acad Sci U S A. 2013;110:7636-41.

9. Meadows AL, Hawkins KM, Tsegaye Y, Antipov E, Kim Y, Raetz L, Dahl RH, Tai A, Mahatdejkul-Meadows T, Xu L, et al. Rewriting yeast central carbon metabolism for industrial isoprenoid production. Nature. 2016;537:694-7.

10. Zhang K, Sawaya MR, Eisenberg DS, Liao JC. Expanding metabolism for biosynthesis of nonnatural alcohols. Proc Natl Acad Sci U S A. 2008:105:20653-8.

11. Lin PC, Saha R, Zhang F, Pakrasi HB. Metabolic engineering of the pentose phosphate pathway for enhanced limonene production in the cyanobacterium Synechocysti s sp. PCC 6803. Sci Rep. 2017;7:17503.

12. Blombach B, Eikmanns BJ. Current knowledge on isobutanol production with Escherichia coli, Bacillus subtilis and Corynebacterium glutamicum. Bioeng Bugs. 2011;2:346-50.

13. Knothe G, Dunn RO. A comprehensive evaluation of the melting points of fatty acids and esters determined by differential scanning calorimetry. J Am Oil Chem Soc. 2009;86:843-56.

14. Knothe G. Improving biodiesel fuel properties by modifying fatty ester composition. Energy Environ Sci. 2009;2:759-66.

15. Janssen HJ, Steinbuchel A. Fatty acid synthesis in Escherichia coli and its applications towards the production of fatty acid based biofuels. Biotechnol Biofuels. 2014;7:7.

16. Meadows CW, Kang A, Lee TS. Metabolic engineering for advanced biofuels production and recent advances toward commercialization. Biotechnol J. 2018;13:1600433.

17. Jiang W, Gu P, Zhang F. Steps towards 'drop-in' biofuels: focusing on metabolic pathways. Curr Opin Biotechnol. 2018;53:26-32.

18. Youngquist JT, Schumacher MH, Rose JP, Raines TC, Politz MC, Copeland MF, Pfleger BF. Production of medium chain length fatty alcohols from glucose in Escherichia coli. Metab Eng. 2013;20:177-86.

19. Mehrer CR, Incha MR, Politz MC, Pfleger BF. Anaerobic production of medium-chain fatty alcohols via a beta-reduction pathway. Metab Eng. 2018;48:63-71. 
20. Liu D, Mannan AA, Han Y, Oyarzun DA, Zhang F. Dynamic metabolic control: towards precision engineering of metabolism. J Ind Microbiol Biotechnol. 2018;45:535-43.

21. Schmitz AC, Hartline CJ, Zhang F. Engineering microbial metabolite dynamics and heterogeneity. Biotechnol J. 2017;12:1700422.

22. Liu D, Evans T, Zhang F. Applications and advances of metabolite biosensors for metabolic engineering. Metab Eng. 2015;31:35-43.

23. Liu D, Hoynes-O'Connor A, Zhang F. Bridging the gap between systems biology and synthetic biology. Front Microbiol. 2013;4:211.

24. Alvarez P, Malcorps P, Almeida AS, Ferreira A, Meyer AM, Dufour JP. Analysis of free fatty-acids, fusel alcohols, and esters in beer-an alternative to Cs2 extraction. J Am Soc Brew Chem. 1994:52:127-34.

25. Hazelwood LA, Daran JM, van Maris AJA, Pronk JT, Dickinson JR. The ehrlich pathway for fusel alcohol production: a century of research on Saccharomyces cerevisiae metabolism. Appl Environ Microbiol. 2008;74:2259-66.

26. Kondo T, Tezuka H, Ishii J, Matsuda F, Ogino C, Kondo A. Genetic engineering to enhance the Ehrlich pathway and alter carbon flux for increased isobutanol production from glucose by Saccharomyces cerevisiae. J Biotechnol. 2012;159:32-7.

27. Li SS, Wen JP, Jia XQ. Engineering Bacillus subtilis for isobutanol production by heterologous Ehrlich pathway construction and the biosynthetic 2-ketoisovalerate precursor pathway overexpression. Appl Microbiol Biotechnol. 2011:91:577-89.

28. Li H, Opgenorth PH, Wernick DG, Rogers S, Wu TY, Higashide W, Malati P, Huo YX, Cho KM, Liao JC. Integrated electromicrobial conversion of $\mathrm{CO}_{2}$ to higher alcohols. Science. 2012;335:1596-1596.

29. Wilbanks B, Trinh CT. Comprehensive characterization of toxicity of fermentative metabolites on microbial growth. Biotechnol Biofuels. 2017;10:262.

30. Iraqui I, Vissers S, Andre B, Urrestarazu A. Transcriptional induction by aromatic amino acids in Saccharomyces cerevisiae. Mol Cell Biol. 1999;19:3360-71.

31. Maclsaac KD, Fraenkel E. Practical strategies for discovering regulatory DNA sequence motifs. PLoS Comput Biol. 2006;2:e36.

32. Lee K, Hahn JS. Interplay of Aro 80 and GATA activators in regulation of genes for catabolism of aromatic amino acids in Saccharomyces cerevisiae. Mol Microbiol. 2013:88:1120-34

33. Hazelwood LA, Tai SL, Boer VM, de Winde JH, Pronk JT, Daran JM. A new physiological role for Pdr12p in Saccharomyces cerevisiae: export of aromatic and branched-chain organic acids produced in amino acid catabolism. FEMS Yeast Res. 2006;6:937-45.

34. Lee K, Sung C, Kim BG, Hahn JS. Activation of Aro80 transcription factor by heat-induced aromatic amino acid influx in Saccharomyces cerevisiae. Biochem Biophys Res Commun. 2013;438:43-7

35. Vuralhan Z, Luttik MA, Tai SL, Boer VM, Morais MA, Schipper D, Almering MJ, Kotter P, Dickinson JR, Daran JM, Pronk JT. Physiological characterization of the ARO10-dependent, broad-substrate-specificity 2-oxo acid decarboxylase activity of Saccharomyces cerevisiae. Appl Environ Microbiol. 2005;71:3276-84.

36. Dickinson JR, Harrison SJ, Hewlins MJ. An investigation of the metabolism of valine to isobutyl alcohol in Saccharomyces cerevisiae. J Biol Chem. 1998:273:25751-6.

37. Matsuda F, Ishii J, Kondo T, Ida K, Tezuka H, Kondo A. Increased isobutanol production in Saccharomyces cerevisiae by eliminating competing pathways and resolving cofactor imbalance. Microb Cell Fact. 2013:12:119.

38. Vogt M, Brusseler C, van Ooyen J, Bott M, Marienhagen J. Production of 2-methyl-1-butanol and 3-methyl-1-butanol in engineered Corynebacterium glutamicum. Metab Eng. 2016;38:436-45.

39. Su HF, Lin JF, Wang YH, Chen Q, Wang GW, Tan FR. Engineering Brevibacterium flavum for the production of renewable bioenergy: C4-C5 advanced alcohols. Biotechnol Bioeng. 2017;114:1946-58.

40. Atsumi S, Higashide W, Liao JC. Direct photosynthetic recycling of carbon dioxide to isobutyraldehyde. Nat Biotechnol. 2009;27:1177-80.

41. Yuan JF, Mishra P, Ching CB. Metabolically engineered Saccharomyces cerevisiae for branched-chain ester productions. J Biotechnol. 2016;239:90-7.

42. Rodriguez GM, Tashiro Y, Atsumi S. Expanding ester biosynthesis in Escherichia coli. Nat Chem Biol. 2014;10:259-65.
43. Guo DY, Zhu J, Deng ZX, Liu TG. Metabolic engineering of Escherichia coli for production of fatty acid short-chain esters through combination of the fatty acid and 2-keto acid pathways. Metab Eng. 2014;22:69-75.

44. Lombard J, Lopez-Garcia P, Moreira D. Phylogenomic investigation of phospholipid synthesis in archaea. Archaea. 2012;2012:630910.

45. Machida S, Bakku RK, Suzuki I. Expression of genes for a flavin adenine dinucleotide-binding oxidoreductase and a methyltransferase from Mycobacterium chlorophenolicum Is necessary for biosynthesis of 10-methyl stearic acid from oleic Acid in Escherichia coli. Front Microbiol. 2017;8:2061.

46. Kaneda T. Iso- and anteiso-fatty acids in bacteria: biosynthesis, function, and taxonomic significance. Microbiol Rev. 1991;55:288-302.

47. Oku H, Kaneda T. Biosynthesis of branched-chain fatty acids in Bacillus subtilis. A decarboxylase is essential for branched-chain fatty acid synthetase. J Biol Chem. 1988;263:18386-96.

48. Kaneda T. Biosynthesis of branched-chain fatty acids. IV. Factors affecting relative abundance of fatty acids produced by Bacillus subtilis. Can J Microbiol. 1966;12:501-14.

49. Choi KH, Heath RJ, Rock CO. beta-Ketoacyl-acyl carrier protein synthase III (FabH) is a determining factor in branched-chain fatty acid biosynthesis. J Bacteriol. 2000;182:365-70.

50. Klein W, Weber MH, Marahiel MA. Cold shock response of Bacillus subtilis: isoleucine-dependent switch in the fatty acid branching pattern for membrane adaptation to low temperatures. J Bacteriol. 1999;181:5341-9.

51. Belitsky BR. Role of branched-chain amino acid transport in Bacillus subtilis CodY activity. J Bacteriol. 2015;197:1330-8.

52. Shivers RP, Sonenshein AL. Activation of the Bacillus subtilis global regulator CodY by direct interaction with branched-chain amino acids. Mol Microbiol. 2004;53:599-611.

53. Shivers RP, Sonenshein AL. Bacillus subtilis ilvB operon: an intersection of global regulons. Mol Microbiol. 2005;56:1549-59.

54. Debarbouille M, Gardan R, Arnaud M, Rapoport G. Role of bkdR, a transcriptional activator of the sigL-dependent isoleucine and valine degradation pathway in Bacillus subtilis. J Bacteriol. 1999;181:2059-66.

55. Madhusudhan KT, Huang N, Braswell EH, Sokatch JR. Binding of L-branched-chain amino acids causes a conformational change in BkdR. J Bacteriol. 1997;179:276-9.

56. Nickel M, Homuth G, Bohnisch C, Mader U, Schweder T. Cold induction of the Bacillus subtilis bkd operon is mediated by increased mRNA stability. Mol Genet Genomics. 2004;272:98-107.

57. Singh AK, Zhang YM, Zhu K, Subramanian C, Li Z, Jayaswal RK, Gatto C, Rock CO, Wilkinson BJ. FabH selectivity for anteiso branched-chain fatty acid precursors in low-temperature adaptation in Listeria monocytogenes. FEMS Microbiol Lett. 2009;301:188-92.

58. Jiang W, Jiang Y, Bentley GJ, Liu D, Xiao Y, Zhang F. Enhanced production of branched-chain fatty acids by replacing beta-ketoacyl-(acyl-carrier-protein) synthase III (FabH). Biotechnol Bioeng. 2015;112:1613-22.

59. Bentley GJ, Jiang W, Guaman LP, Xiao Y, Zhang F. Engineering Escherichia coli to produce branched-chain fatty acids in high percentages. Metab Eng. 2016;38:148-58.

60. Haushalter RW, Kim W, Chavkin TA, The L, Garber ME, Nhan M, Adams PD, Petzold CJ, Katz L, Keasling JD. Production of anteiso-branched fatty acids in Escherichia coli; next generation biofuels with improved coldflow properties. Metab Eng. 2014;26:111-8.

61. Tao H, Guo D, Zhang Y, Deng Z, Liu T. Metabolic engineering of microbes for branched-chain biodiesel production with low-temperature property. Biotechnol Biofuels. 2015;8:92.

62. Carreto L, Moore E, Nobre MF, Wait R, Riley PW, Sharp RJ, Da Costa MS. Rubrobacter xylanophilus sp. nov., a New thermophilic species isolated from a thermally polluted effluent. Int J Syst Evol Microbiol. 1996:46:460-5.

63. Miralles J, Barnathan G, Galonnier R, Sall T, Samb A, Gaydou EM, Kornprobst JM. New branched-chain fatty acids from the Senegalese gorgonian Leptogorgia piccola (white and yellow morphs). Lipids. 1995:30:459-66.

64. Dembitsky VM, Srebnik M. Variability of hydrocarbon and fatty acid components in cultures of the filamentous cyanobacterium Scytonema sp. isolated from microbial community "black cover" of limestone walls in Jerusalem. Biochemistry (Mosc). 2002;67:1276-82. 
65. Lennarz WJ, Scheuerbrandt G, Bloch K. The biosynthesis of oleic and 10-methylstearic acids in Mycobacterium phlei. J Biol Chem. 1962;237:664-71.

66. Brennan PJ, Nikaido H. The envelope of mycobacteria. Annu Rev Biochem. 1995;64:29-63.

67. Bao XM, Katz S, Pollard M, Ohlrogge J. Carbocyclic fatty acids in plants: biochemical and molecular genetic characterization of cyclopropane fatty acid synthesis of Sterculia foetida. Proc Natl Acad Sci U S A. 2002;99:7172-7.

68. Poger D, Caron B, Mark AE. Effect of methyl-branched fatty acids on the structure of lipid bilayers. J Phys Chem B. 2014;118:13838-48.

69. Pond JL, Langworthy TA. Effect of Growth temperature on the longchain diols and fatty-acids of Thermomicrobium roseum. J Bacteriol. 1987;169:1328-30.

70. Bansal-Mutalik R, Nikaido H. Mycobacterial outer membrane is a lipid bilayer and the inner membrane is unusually rich in diacyl phosphatidylinositol dimannosides. Proc Natl Acad Sci U S A. 2014;111:4958-63.

71. Guerardel Y, Maes E, Briken V, Chirat F, Leroy Y, Locht C, Strecker G, Kremer L. Lipomannan and lipoarabinomannan from a clinical isolate of Mycobacterium kansasii: novel structural features and apoptosisinducing properties. J Biol Chem. 2003;278:36637-51.

72. Alvarez HM, Souto MF, Viale A, Pucci OH. Biosynthesis of fatty acids and triacylglycerols by 2,6,10,14-tetramethyl pentadecane-grown cells of Nocardia globerula 432. FEMS Microbiol Lett. 2001;200:195-200.

73. Akamatsu Y, Law JH. Enzymatic alkylenation of phospholipid fatty acid chains by extracts of Mycobacterium phlei. J Biol Chem. 1970;245:701-8.

74. Meena LS, Chopra P, Vishwakarma RA, Singh Y. Biochemical characterization of an S-adenosyl-L-methionine-dependent methyltransferase (Rv0469) of Mycobacterium tuberculosis. Biol Chem. 2013;394:871-7.

75. Meena LS, Kolattukudy PE. Expression and characterization of Rv0447c product, potentially the methyltransferase involved in tuberculostearic acid biosynthesis in Mycobacterium tuberculosis. Biotechnol Appl Biochem. 2013:60:412-6.

76. Goelz SE, Cronan JE Jr. The positional distribution of fatty acids in Escherichia coli phospholipids is not regulated by sn-glycerol 3-phosphate levels. J Bacteriol. 1980;144:462-4.

77. Gilleron M, Lindner B, Puzo G. MS/MS approach for characterization of the fatty acid distribution on mycobacterial phosphatidyl-myo-inositol mannosides. Anal Chem. 2006;78:8543-8.

78. Gilleron M, Quesniaux VF, Puzo G. Acylation state of the phosphatidylinositol hexamannosides from Mycobacterium bovis bacillus Calmette Guerin and Mycobacterium tuberculosis H37Rv and its implication in Toll-like receptor response. J Biol Chem. 2003;278:29880-9.

79. Asakura H, Ekawa T, Sugimoto N, Momose Y, Kawamoto K, Makino S, Igimi S, Yamamoto S. Membrane topology of Salmonella invasion protein SipB confers osmotolerance. Biochem Biophys Res Commun. 2012:426:654-8.

80. Hara H, Hyono A, Kuriyama S, Yano I, Masui M. ESR studies on the membrane properties of a moderately halophilic bacterium. II. Effect of extreme growth conditions on liposome properties. J Biochem. 1980:88:1275-82.

81. Brown JL, Ross T, McMeekin TA, Nichols PD. Acid habituation of Escherichia coli and the potential role of cyclopropane fatty acids in low pH tolerance. Int J Food Microbiol. 1997;37:163-73.

82. Alvarez-Ordonez A, Fernandez A, Lopez M, Arenas R, Bernardo A. Modifications in membrane fatty acid composition of Salmonella typhimurium in response to growth conditions and their effect on heat resistance. Int J Food Microbiol. 2008;123:212-9.

83. Shabala L, Ross T. Cyclopropane fatty acids improve Escherichia coli survival in acidified minimal media by reducing membrane permeability to $\mathrm{H}^{+}$and enhanced ability to extrude $\mathrm{H}^{+}$. Res Microbiol. 2008;159:458-61.

84. Pini CV, Bernal P, Godoy P, Ramos JL, Segura A. Cyclopropane fatty acids are involved in organic solvent tolerance but not in acid stress resistance in Pseudomonas putida DOT-T1E. Microb Biotechnol. 2009;2:253-61.

85. Glickman MS, Cox JS, Jacobs WR. A novel mycolic acid cyclopropane synthetase is required for cording, persistence, and virulence of Mycobacterium tuberculosis. Mol Cell. 2000;5:717-27.

86. Grogan DW, Cronan JE Jr. Cyclopropane ring formation in membrane lipids of bacteria. Microbiol Mol Biol Rev. 1997;61:429-41.

87. Hildebrand JG, Law JH. Fatty acid distribution in bacterial phospholipids. The specificity of the cyclopropane synthetase reaction. Biochemistry. 1964;3:1304-8.

88. Bao X, Thelen JJ, Bonaventure G, Ohlrogge JB. Characterization of cyclopropane fatty-acid synthase from Sterculia foetida. J Biol Chem. 2003;278:12846-53.

89. Chang YY, Eichel J, Cronan JE Jr. Metabolic instability of Escherichia coli cyclopropane fatty acid synthase is due to $\mathrm{RpoH}$-dependent proteolysis. J Bacteriol. 2000;182:4288-94.

90. Machida S, Shiraiwa Y, Suzuki I. Construction of a cyanobacterium synthesizing cyclopropane fatty acids. Biochim Biophys Acta. 2016;1861:980-7.

91. Zhao Y, Hindorff LA, Chuang A, Monroe-Augustus M, Lyristis M, Harrison ML, Rudolph FB, Bennett GN. Expression of a cloned cyclopropane fatty acid synthase gene reduces solvent formation in Clostridium acetobutylicum ATCC 824. Appl Environ Microbiol. 2003;69:2831-41.

92. Chang YY, Cronan JE Jr. Membrane cyclopropane fatty acid content is a major factor in acid resistance of Escherichia coli. Mol Microbiol. 1999;33:249-59.

93. Kim BH, Kim S, Kim HG, Lee J, Lee IS, Park YK. The formation of cyclopropane fatty acids in Salmonella enterica serovar Typhimurium. Microbiology. 2005;151:209-18.

94. Yu XH, Prakash RR, Sweet M, Shanklin J. Coexpressing Escherichia coli cyclopropane synthase with Sterculia foetida Lysophosphatidic acid acyltransferase enhances cyclopropane fatty acid accumulation. Plant Physiol. 2014;164:455-65.

95. Tan Z, Yoon JM, Chowdhury A, Burdick K, Jarboe LR, Maranas CD, Shanks $J$. Engineering of $E$. coli inherent fatty acid biosynthesis capacity to increase octanoic acid production. Biotechnol Biofuels. 2018;11:87.

96. Liu D, Zhang F. Metabolic feedback circuits provide rapid control of metabolite dynamics. ACS Synth Biol. 2018;7:347-56.

97. Xiao Y, Bowen CH, Liu D, Zhang F. Exploiting nongenetic cell-to-cell variation for enhanced biosynthesis. Nat Chem Biol. 2016;12:339-44.

98. Bastian S, Liu X, Meyerowitz JT, Snow CD, Chen MM, Arnold FH. Engineered ketol-acid reductoisomerase and alcohol dehydrogenase enable anaerobic 2-methylpropan-1-ol production at theoretical yield in Escherichia coli. Metab Eng. 2011;13:345-52.

99. Baez A, Cho KM, Liao JC. High-flux isobutanol production using engineered Escherichia coli: a bioreactor study with in situ product removal. Appl Microbiol Biotechnol. 2011;90:1681-90.

100. Yamamoto S, Suda M, Niimi S, Inui M, Yukawa H. Strain optimization for efficient isobutanol production using Corynebacterium glutamicum under oxygen deprivation. Biotechnol Bioeng. 2013;110:2938-48.

101. Park SH, Kim S, Hahn JS. Metabolic engineering of Saccharomyces cerevisiae for the production of isobutanol and 3-methyl-1-butanol. Appl Microbiol Biotechnol. 2014:98:9139-47.

102. Cann AF, Liao JC. Production of 2-methyl-1-butanol in engineered Escherichia coli. Appl Microbiol Biotechnol. 2008;81:89-98.

103. Yuan J, Chen X, Mishra P, Ching CB. Metabolically engineered Saccharomyces cerevisiae for enhanced isoamyl alcohol production. Appl Microbiol Biotechnol. 2017;101:465-74. 